\title{
COMPARATIVE STUDY BETWEEN THE EFFECT OF CLASS II AMALGAM AND COMPOSITE RESTORATIONS IN POSTERIOR TEETH ON PERIODONTAL TISSUES HEALTH
}

\author{
Yasser Al-Fawaz* Raneem Alofi** and Hafez Diab ${ }^{* * *}$
}

\begin{abstract}
Aim of the study: To investigate and compare the effect of class II amalgam and composite restorations on periodontal tissues health.

Materials \& Methods: The gingival index, plaque index, probing depth and clinical attachment level of one hundred teeth (50 restored by class II amalgam filling and 50 restored by class II composite filling) were included in the present study. One hundred teeth were classified into two groups as follows: Group I: involved 50 teeth restored by class II amalgam filling. Group II: involved 50 teeth restored by class II composite filling. The data was analyzed comparing both groups. The descriptive statistics included the mean, range and standard deviation for both groups.
\end{abstract}

Results: Our results showed that there is statistically significant decrease in GI, PPD and CAL scores of amalgam group compared to composite group. Whereas there is no statistically significant in PD scores between both groups

Conclusions: Class II composite restorations appear to be associated with periodontal breakdown more than class II amalgam restoration.

\section{INTRODUCTION}

Dental restorations and periodontal health are inseparably interrelated. The type of restoration, the adaptation of the margins, the contours of the restoration, the proximal relationships and the surface smoothness have a critical biological impact on the gingiva and the supporting periodontal tissues ${ }^{[1]}$. Dental restorations therefore play a significant role in maintaining periodontal health Maintenance of a healthy periodontium is fundamental for the long term success of class II dental restorations. So, class II restorations may affect the periodontal health if the distances between the junctional epithelium and supracrestal connective tissue attachment aren't respected, or if there is insufficient space to maintain the health of the interproximal tissues,

*Lecturer, Department of Restorative Dental Sciences, College of Dentistry, King Saud University.

** Assistant professor, Department of Restorative Dental Sciences, College of Dentistry, King Saud University.

***Professor of Periodontology, Riyadh Colleges of Dentistry and Pharmacy. and Faculty of Dentistry, Tanta University. 
leading to gingival inflammation, connective tissue attachment loss and bone resorption ${ }^{[2]}$.

Dental amalgam containing mercury has been condemned because of its toxicity and hence to be damaging of harmful to the general health. It must be clear that many sensational, confusing and misleading reports have been published. Today there is evidence that dental amalgam in the oral cavity does not harm anyone's health ${ }^{[3]}$. For those who are condemning amalgam there an abundant number of alarming reports taking into consideration the biologic effects of resin composites: methacrylate allergy for dentists and dental technicians, the threefinger-syndrome due to contact with liquid resin, allergic reactions at the level of the airways and breathing problems caused by dust particles (esp. composite particles after polishing procedures) have been described. It can be concluded that dental amalgam is not more toxic than resin composite in light of both patients' and dental care providers' health. Recent investigations demonstrated higher than expected health risks with resin composites ${ }^{[4]}$.

Healing of the gingival tissue is mandatory before applying the restorative dental treatment, mainly if the cervical margin of the obturation must be placed subgingivally ${ }^{[5]}$. In order to protect and maintain the health status of the gingival tissues, the following methods can be applied: rubber dam, wedges, matrices, retraction cord, and local removal of excessive gingival tissues (by help of solutions, electrical cauterization, LASER, etc.) or surgical alteration of gingival architecture ${ }^{[6]}$. In order to achieve an adequate restorative treatment, maintenance of adequate dental anatomy should be taken into account, by achieving correct occlusal, proximal, vestibular, oral and cervical anatomy ${ }^{[7]}$. Existing plastic restorations, if inadequate, might be remodeled and polished, if by this manner they can be improved. Gingival trauma should be minimal, in every clinical procedure of the restorative treatment ${ }^{[8]}$.
The two direct dental restorative materials most commonly used today are silver-mercury amalgam and resin-based composite ${ }^{[9]}$. The survival of dental amalgam restorations is twice as high as for composite fillings: polymerization shrinkage, deficient marginal adaptation, higher wear rates, defective contact points leading to food impaction, insufficiently converted composite at the bottom of the cavity are problems that cannot be underestimated when using resin-composite ${ }^{[10]}$. This does not imply that there is no weakness for amalgam: the need for retentive cavities at the cost of healthy tooth substance, weakening of the tooth's strength by cutting through the tooth crown's ridges, the risk of fracture of remaining tooth substance (mostly buccal and lingual surfaces) as the result of the cavity design, and the lack of adhesion between amalgam and tooth substance ${ }^{[11]}$. Retaining a tooth's strength by the replacement of amalgam by resin-composites is not always the correct solution. In this respect, it can be questioned whether it is not appropriate to repair failing (extensive) amalgam restorations as to replace them with resin-composites ${ }^{[12]}$. Research in this respect has demonstrated that dentists still are not convinced of this treatment option. Restoring a tooth in its original build-up or structure and function within the oral cavity is the basis of the biomimetic principle: the use of composite appears to be more obvious than restoring with amalgam ${ }^{[13]}$. Dental restorations and periodontal healthcare closely related: periodontal health is needed for the correct functioning of all restorations while the functional stimulation due to dental restorations is essential for periodontal protection ${ }^{[14]}$. In the present study we compare the effect of class II amalgam and composite restorations on periodontal tissues health.

\section{MATERIALS AND METHODS}

The gingival index, plaque index, probing depth and clinical attachment level of one hundred teeth (50 restored by class II amalgam filling and 50 restored by class II composite filling) were included in the present study. 
The criteria of inclusion include tooth having class II amalgam or class II composite filling in posterior teeth, no overhanging restorations, and tooth is vital and the restorations were done from 6 months to 3 years ago. The exclusion criteria include smoking, pregnancy, history of systemic diseases and those who had periodontal surgery.

One hundred teeth were classified into two groups as follows:

Group I: involved 50 teeth restored by class II amalgam filling.

Group II: involved 50 teeth restored by class II composite filling.

The following parameters will be evaluated for every tooth

1- Gingival Index (GI) described by Löe and Silness $1963^{[15]}$.

2- Plaque Index (PI) described by Silness and Löe $1964^{[16]}$.

3- Probing pocket depth (PPD) according to Ramfjord, $1967^{[17]}$.
4- Clinical attachment loss (CAL) according to Ramfjord, $1967^{[17]}$.

The PPD and CAL measurements were carried out at six sites for every tooth (mesiobuccal, midbuccal, distobuccal, mesiolingual, midlingual and distolingual) using UNC manual probe. The mean score in millimeter for individual tooth was calculated by summing the scores of each site and dividing by the total number of sites. Two periodontists examine all sites and the overall Kappa score of 0.96 was achieved for intra-examiner variability and 0.90 for inter-examiner variability.

The recorded data were compiled and entered in a computer using Statistical Package for Social Sciences (SPSS) version 20.0 software (Chicago, IL, USA). One way ANOVA and Chi-square tests were used for comparisons. A p-value of less than 0.05 was considered as statistically significant. The data was analyzed comparing both groups. The descriptive statistics included the mean, range and standard deviation for both groups.

\section{The clinical sheet form for the present study}

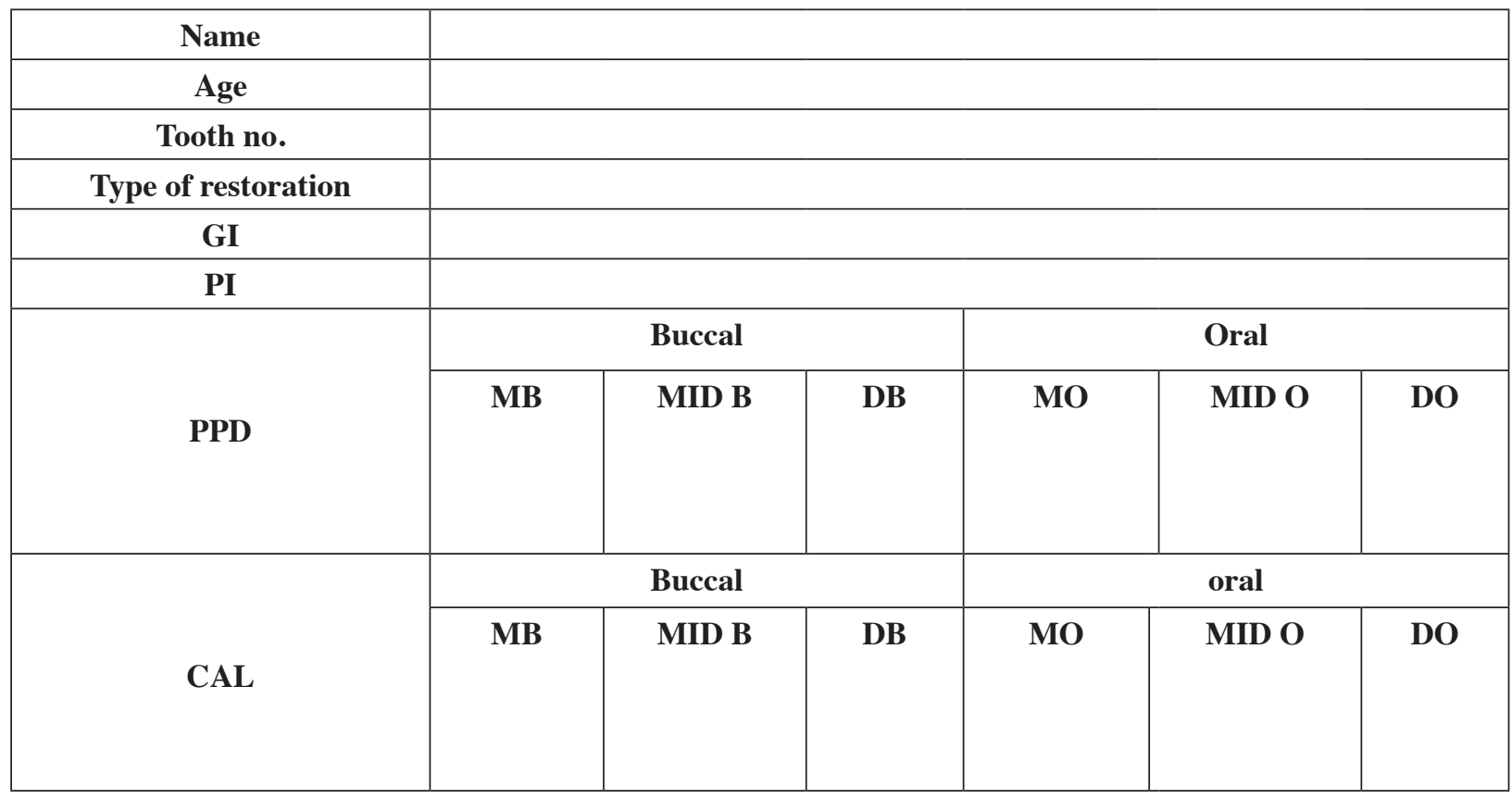




\section{RESULTS}

The study evaluated the GI, PI, PPD and CAL among 50 restored class II amalgam filling (group I) teeth and 50 restored class II composite filling (group II) teeth. The age range in both groups was between 18-40 years with average age 26.5 years. Since there was uneven distribution of gender, data was not analyzed according to the gender.

(Table 1) describes the minimum, maximum and mean scores along with the standard deviation for GI, PI, PPD and CAL. The mean of the GI score in the composite group (1.58) was higher than that of the amalgam group (1.24). The mean GI score of (1.58) in the composite group was even higher than the mean (1.41) of the overall combined groups. Similarly, the PI mean score of the composite group (1.73) was higher than that of the amalgam group (1.57) as well as the mean PI score of the overall group (1.65). ALSO, the mean of the PD score in the composite group (2.85) was higher than that of the amalgam group (2.66). The mean PD score of (1.58) in the composite group was even higher than the mean (2.735) of the overall combined groups. Similarly, the CAL mean score of the composite group (1.86) was higher than that of the amalgam group (1.52) as well as the mean PI score of the overall group (1.685).

Our results showed that there is statistically significant decrease in GI, PPD and CAL scores of amalgam group compared to composite group. Whereas there is no statistically significant in PD scores between both groups (table $2 \&$ figure 1 ).

Table (3) shows one way ANOVA of mean GI, mean PI, mean PPD and the mean CAL in the amalgam and composite group. In all the variables there was a statistically significant difference, $\mathrm{p}<0.05$ between the composite and the amalgam group.

TABLE (1) Shows the average (mean) scores of gingival index GI, plaque index PI, Probing pocket depth PPD and Clinical attachment loss CAL.

\begin{tabular}{|c|c|c|c|c|c|}
\hline & & GI & PI & PPD & CAL \\
\hline \multirow{5}{*}{$\begin{array}{c}\text { Group I } \\
\text { class II amalgam } \\
\text { filling }\end{array}$} & $\mathrm{N}$ & 50 & 50 & 50 & 50 \\
\hline & Minimum & 0.91 & 1.29 & 1.75 & 0 \\
\hline & Maximum & 2.15 & 2.43 & 3.50 & 2.53 \\
\hline & Mean & 1.24 & 1.57 & 2.66 & 1.52 \\
\hline & Std. Deviation & 0.45243 & 0.21248 & 0.36570 & 0.27530 \\
\hline \multirow{5}{*}{$\begin{array}{c}\text { Group II } \\
\text { class II } \\
\text { composite filling }\end{array}$} & $\mathrm{N}$ & 50 & 50 & 50 & 50 \\
\hline & Minimum & 0.98 & 1.35 & 1.93 & 0 \\
\hline & Maximum & 2.64 & 2.81 & 4.21 & 3.05 \\
\hline & Mean & 1.58 & 1.73 & 2.85 & 1.86 \\
\hline & Std. Deviation & 0.35371 & 0.20527 & 0.42682 & 0.25480 \\
\hline \multirow{5}{*}{ Total } & $\mathrm{N}$ & 100 & 100 & 100 & 100 \\
\hline & Minimum & 0.91 & 1.29 & 1.75 & 0 \\
\hline & Maximum & 2.64 & 2.81 & 4.21 & 3.05 \\
\hline & Mean & 1.41 & 1.65 & 2.735 & 1.685 \\
\hline & Std. Deviation & 0.40307 & 0.208875 & 039626 & 0.26505 \\
\hline
\end{tabular}




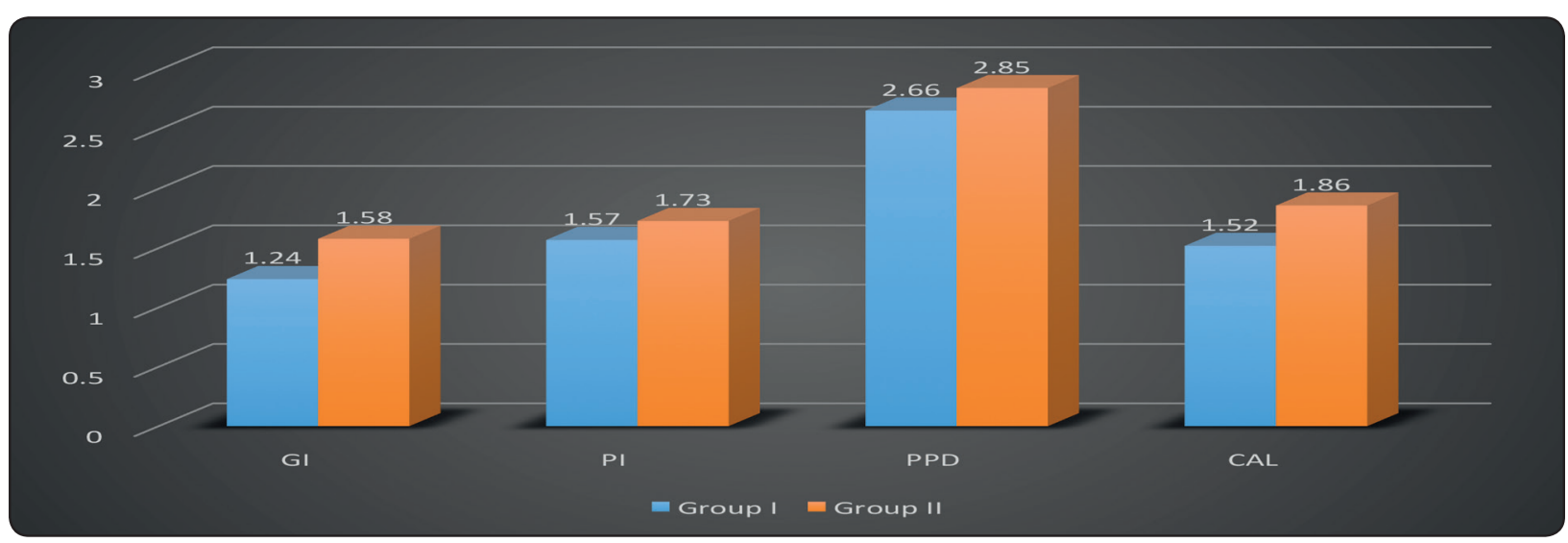

Fig. (1) Shows graphical comparison of mean GI, PI, PPD and CAL in group I (amalgam filling) and group II (composite filling).

TABLE (2) Shows the mean \pm SD of mean GI, PI, PPD and CAL in group I (amalgam filling) compared group II (composite filling).

\begin{tabular}{|c|c|c|c|}
\hline & Group I & Group II & P \\
\hline GI & $1.24 \pm 0.45243$ & $1.58 \pm 0.35371$ & $<0.05$ \\
\hline PI & $1.57 \pm 0.21248$ & $1.73 \pm 0.20527$ & $>0.05$ \\
\hline PPD & $2.66 \pm 0.36570$ & $2.85 \pm 0.42682$ & $<0.05$ \\
\hline CAL & $1.52 \pm 0.27530$ & $1.86 \pm 0.25480$ & $<0.05$ \\
\hline
\end{tabular}

TABLE (3) Shows one way ANOVA of GI, PI, PPD and CAL with respect to the amalgam and composite group.

\begin{tabular}{|c|c|c|c|c|c|c|}
\hline \multicolumn{7}{|c|}{ One Way ANOVA } \\
\hline & & Sum of Squares & $\mathrm{df}$ & Mean Square & $\mathrm{F}$ & Sig. \\
\hline \multirow{3}{*}{ GI } & Between groups & 6.173 & 1 & 6.173 & 8.954 & \multirow[t]{3}{*}{$0.008 *$} \\
\hline & Within groups & 55.745 & 98 & 0.585 & & \\
\hline & Total & 61.918 & 99 & & & \\
\hline \multirow{3}{*}{ PI } & Between groups & 5.732 & 1 & 5.732 & 15.324 & \multirow[t]{3}{*}{$0.001 *$} \\
\hline & Within groups & 43.269 & 98 & 0.476 & & \\
\hline & Total & 49.001 & 99 & & & \\
\hline \multirow{3}{*}{ PPD } & Between groups & 7.345 & 1 & 7.345 & 5.216 & \multirow[t]{3}{*}{$0.011 *$} \\
\hline & Within groups & 47.294 & 98 & 2.468 & & \\
\hline & Total & 54.639 & 99 & & & \\
\hline \multirow{3}{*}{ CAL } & Between groups & 6.386 & 1 & 6.386 & 6.284 & \multirow[t]{3}{*}{$0.014 *$} \\
\hline & Within groups & 51.340 & 98 & 1.364 & & \\
\hline & Total & 57.726 & 99 & & & \\
\hline
\end{tabular}

\footnotetext{
* Significant at $p<0.05$
} 


\section{DISCUSSION}

In this retrospective clinical study that was designed to evaluated the GI, PI, PPD and CAL among 50 restored class II amalgam filling (group I) teeth and 50 restored class II composite filling (group II) teeth. The results showed that there is statistically significant decrease in GI, PPD and CAL scores of amalgam group compared to composite group. Whereas there is no statistically significant differences in PD scores between both groups. These results indicated that class II composite restorations have more negative effect on periodontium compared with class II amalgam. Our results were consistent with those described by many comparative studies ${ }^{[18-21]}$. However, other studies concluded that class II amalgam restorations was more injurious to periodontium compared to other restorative materials ${ }^{[22,23]}$.

Our results may be attributed to the surfaces of composite resin was found to be altered upon exposure to saliva, with the deposition of a carbon-nitrogen-rich conditioning film ${ }^{[24]}$. Also, failure rates and higher risk of secondary caries are associated with resin composite than with amalgam restorations ${ }^{[25,26]}$. On the other hand, marginal deterioration of composite restorations remains problematic and is the major reason for the short lifetime of these adhesive restorations ${ }^{[27,28]}$.

Currently, direct composite restorations are only indicated when patients have excellent oral hygiene, due to the greater adherence of plaque that occurs on this type of materials ${ }^{[29]}$. The higher probability of having more plaque adhesion on resin-based materials than in amalgam, calls for even more detailed instructions that have to be given to the patient, regarding oral hygiene, when these materials are selected ${ }^{[30]}$.Thus, a flawless restoration placement and, simultaneously, appropriate oral hygiene, have a positive effect increasing the longevity of restorations and decreasing their need of replacement ${ }^{[31,32]}$.

\section{CONCLUSIONS}

Within the limitation of this study it concluded that Class II composite restorations appear to be associated with periodontal breakdown more than class II amalgam restoration.

\section{REFERENCES}

1- Rasines Alcaraz MG, Veitz-Keenan A, Sahrmann P, et al. Direct composite resin fillings versus amalgam fillings for permanent of adult posterior teeth. Cochrane Database Syst Rev 2014:CD005620.

2- Sjögren P, Halling A. Survival time of class II molar restorations in relation to patient and dental health insurance costs for treatment. Swedish Dental Journal2002; 26:59-66.

3- Fuks AB. The use of amalgam in pediatric dentistry. Pediatric Dentistry 2002; 24:448-55.

4- $\quad$ Lynch CD, Opdam NJ, Hickel R, Brunton PA, Gurgan S, Kakaboura A, et al. Guidance on posterior resin composites: Academy of Operative Dentistry - European Section. Journal of Dentistry 2014; 42:377-83.

5- Zöchbauer H. Number of dental restorations worldwide. Market Research Ivoclar Vivadent; 2011.

6- Kim K-L, Namgung C, Cho B-H. The effect of clinical performance on the survival estimates of direct restorations. Restor Dent Endod 2013; 38(1):11-20.

7- Manhart J, Chen H, Hamm G, Hickel R. Buonocore memorial lecture. Review of the clinical survival of direct and indirect restorations in posterior teeth of the permanent dentition. Operative Dentistry 2004; 29:481-508.

8- Heintze SD, Rousson V. Clinical effectiveness of direct class II restorations - a meta-analysis. Journal of Adhesive Dentistry2012; 14:407-31

9- Mjör IA. The reasons for replacement and the age of failed restorations in general dental practice. Acta Odontologica Scandinavica 1997; 55:58-63.

10- Wilson MA, Cowan AJ, Randall RC, Crisp RJ, Wilson NH. A practice-based, randomized, controlled clinical trial of anew resin composite restorative: one-year results. Operative Dentistry 2002; 27:423-9.

11- Bernardo M, Luis H, Martin MD, Leroux BG, Rue T, Leita o J,et al. Survival and reasons for failure of amal- 
gam versus composite posterior restorations placed in a randomized clinical trial. Journal of American Dental Association 2007 ; $138: 775-83$.

12- Higgins JPT, Green S, editors. Cochrane handbook for systematic reviews of interventions 4.2.6 [updated September2006]. The Cochrane Library; 2006. p. 4.

13- Moher D, Liberati A, Tetzlaff J, Altman DG. PRISMA Group. Preferred reporting items for systematic reviews and met analyses: the PRISMA statement. Annals of Internal Medicine2009; 151:264-9.

14- Wells GA, Shea B, O'Connel D, Peterson J, Welch V, Losos M,et al. The Newcastle-Ottawa Scale (NOS) for assessing the quality of nonrandomized studies in meta-analysis.2000.Availablefrom:http://www.ohri.ca/programs/ clinical_epidemiology/oxford.asp [accessed 22.03.15].

15- Loe H and Silness J. Periodontal disease in pregnancy I prevalence and severity. Acta Odontol Scand 1963; 21:533-551.

16- Silness $\mathrm{J}$ and Loe H. Periodontal disease in pregnancy II. Correlation between oral hygiene and and periodontal condition. Acta Odontol Scand 1964; 22:121-135.

17- Ramflord S. The periodontal index. J Periodontol. 1967, 38:602.

18- Johnson GH, Bales DJ, Gordon GE, Powell LV. Clinical performance of posterior composite resin restorations. Quintessence International 1992; 23:705-11.

19- Mjör IA, Kokstad A. Five-year study of Class II restorations in permanent teeth using amalgam, glass polyalkenoate (ionomer) cement and resin-based composite materials. Journal of Dentistry 1993; 21:338-43.

20- Collins CJ, Bryant RW, Hodge KL. A clinical evaluation of posterior composite resin restorations: 8-year findings. Journal of Dentistry 1998; 26:311-7.

21- Mair LH. Ten-year clinical assessment of three posterior resin composites and two amalgams. Quintessence International 1998; 29:483-90.
22- Levin L, Coval M, Geiger SB. Cross-sectional radiographic survey of amalgam and resin-based composite posterior restorations. Quintessence International 2007; 38:511-4.

23- Kim KL, Namgung C, Cho BH. The effect of clinical performance on the survival estimates of direct restorations. Restorative Dentistry \& Endodontics 2013; 38:11-20.

24- Landis JR, Koch GG. The measurement of observer agreement for categorical data. Biometrics 1977; 33:159-74.

25- Shrier I, Boivin JF, Steele RJ, Platt RW, Furlan A, Kakuma $\mathrm{R}$,et al. Should meta-analyses of interventions include observational studies in addition to randomized controlled trials? A critical examination of underlying principles. American Journal of Epidemiology 2007; 166:1203-9.

26- Pihlstrom BL, Curran AE, Voelker HT, Kingman A.Randomized controlled trials: what are they and who needs them? Periodontology 2000; 59:14-31.

27- Letzel H, van't Hof MA, Marshall GW, Marshall SJ. The influence of the amalgam alloy on the survival of amalgam restorations: a secondary analysis of multiple controlled clinical trials. Journal of Dental Research 1997; 76:1787-98.

28- Roulet JF. Longevity of glass ceramic inlays and amalgam -results up to 6 years. Clinical Oral Investigations 1997; $1: 40-6$.

29- Hurst D. Amalgam or composite fillings - which material lasts longer? Evidence-Based Dentistry 2014; 15:50-1.

30- Burke FJ, Wilson NH, Cheung SW, Mjo“ r IA. Influence of patient factors on age of restorations at failure and reasons for their placement and replacement. Journal of Dentistry2001; 29:317-24.

31- Forss H, Widstro“m E. The post-amalgam era: a selection of materials and their longevity in the primary and young permanent dentitions. International Journal of Paediatric Dentistry 2003; 13:158-64.

32- Grossman ES, Matejka JM. Effect of restorative materials and in vitro carious challenge on amalgam margin quality. Journal of Prosthetic Dentistry 1996; 76:239-45. 